\title{
Aggressive Behaviour Exhibited by a San Joaquin Kit Fox, Vulpes macrotis mutica
}

HOWARD O. CLARK, JR.

California State University, Stanislaus. Endangered Species Recovery Program. 1900 North Gateway Boulevard, Suite 101, Fresno, California, 93727-1622, USA.

Current address: H.T. Harvey \& Associates, 423 West Fallbrook, Suite 202, Fresno, California 93711-6138, USA.

Clark, Howard O., Jr. 2005. Aggressive behaviour exhibited by a San Joaquin Kit Fox Vulpes macrotis mutica. Canadian FieldNaturalist 119(1): 134.

While placing a hairtube-trapping device near a Kit Fox natal den, I observed a juvenile Kit Fox exhibit aggressive behaviour towards my presence. Although Kit Foxes usually are not aggressive, my observation demonstrated that some Kit Foxes defend their natal dens when alarmed.

Key Words: San Joaquin Kit Fox, Vulpes macrotis mutica, aggressive behaviour, natal den, California.

Kamler et al. (2000) reported an incident where a juvenile male Swift Fox (Vulpes velox) exhibited aggressive behaviors toward researchers. Like the Swift Fox, Kit Foxes are usually acquiescent and do not readily display aggression toward humans (when not trapped). Similar to the observations of Kamler et al. (2000), I witnessed the aggressive behaviour of a radiocollared juvenile Kit Fox as I was placing prototype hairtube traps (Clark et al. 2003) in the vicinity of its natal den. As I was placing the trap, the male pup aggressively approached me with a series of sharp barks. He circled around me within $3 \mathrm{~m}-$ sniffing and barking. He then stuck his head into the hairtube trap twice while I was watching him, but did not remove any bait. He continued to pace around me and bark for about 10 min. This observation occurred at 20:45 on 25 May 1999, along the California Aqueduct, near Lost Hills, Kern County, California, 35³6.98'N, 11941.66'W (WGS84/NAD83). It was dark at the time; sunset was at 20:03. The natal den was being used by two adult (male and female) Kit Foxes and three male pups. All five Kit Foxes were radio-collared, with the juveniles being trapped and radio-collared on 3 May 1999.

It appeared that the juvenile was protecting the natal den area and was curious to discover my reaction toward his aggressive approaches. Aggressive foxes that readily approach potential danger might experience a higher rate of mortality than those that select to run and take cover in dens. By November 1999, two of these juveniles were killed by Coyotes (Canis latrans) and one had presumably dispersed (Clark 2001). Coyotes are a common source of mortality for Kit Foxes (Ralls and White 1995). My observation suggests that some Kit Foxes will defend their natal areas and aggressively approach potential threats to themselves and family members, as also described in Kamler et al. (2000).

\section{Acknowledgments}

The California Department of Water Resources gave permission to enter the California Aqueduct right-of-way. Funding of this note provided by the U.S. Department of the Interior, Bureau of Reclamation. J. Clark also witnessed the fox interaction.

\section{Literature Cited}

Clark, H. O., Jr. 2001. Endangered San Joaquin Kit Fox and Non-native Red Fox: Interspecific Competitive Interactions. M.S. thesis, California State University, Fresno. 54 pages.

Clark, H. O., Jr., B. L. Cypher, P. A. Kelly, D. F. Williams, and S. D. Clifton. 2003. Use of a hair-sampling tube to detect the San Joaquin Kit Fox. Transactions of the Western Section of the Wildlife Society. 38/39: 29-30.

Kamler, J. F., W. B. Ballard, and K. Mote. 2000. Aggressive behavior exhibited by a Swift Fox, Vulpes velox. Canadian Field-Naturalist 114: 506.

Ralls, K., and P. J. White. 1995. Predation on San Joaquin Kit Foxes by larger canids. Journal of Mammalogy 76: 723 729.

Received 29 March 2004

Accepted 7 March 2005 